\title{
Electron Microscopic Immunocytochemistry on the Colocaliza- tion of ATP Synthase and Cytochrome P-450 of Side Chain Cleavage Enzymes in Mitochondria of Rat and Bovine Adrenal Cortical Cells
}

\author{
Tomoko Yoshinaga-HirabaYashi ${ }^{1}$, Hideaki Tsuri ${ }^{1}$, Kazunori Ishimura ${ }^{2}$ and Tadao Hashimoto ${ }^{3}$ \\ Departments of Anatomy ${ }^{1}$ and Physiological Chemistry ${ }^{3}$, Osaka University Medical School, Suita; and Department of Anatomy ${ }^{2}$, \\ Tokushima University School of Medicine, Tokushima, Japan
}

Received August 17, 1992

Summary. To clarify whether ATP synthase and side chain cleavage enzymes (SCC) can coexist in a mitochondrion of the adrenal cortical cell, and whether the functional heterogenity of mitochondria can occur in an adrenal cortical cell, the immunostainability of these two enzymes in mitochondria was compared by electron microscope using pre- and post-embedding methods.

In the pre-embedding method, the inner membrane of most mitochondria in the adrenal cortical cell was positively stained for SCC, 11 $\beta$-hydroxylase, and ATP synthase, but among these immunopositive mitochondria we often observed negatively immunoreacted ones in the same adrenal cortical cell. In the positively stained mitochondria, immunoreaction products were evenly localized along the inner mitochondrial membrane. We therefore think that these differences in the immunostainability are caused by technical artifacts, namely the inadequent penetration of the antibody.

In the post-embedding immunocytochemistry, gold particles showing the presence of the enzymes were observed on all mitochondria. Two different antibodies, anti-ATP synthase antibody and anti-cytochrome $P$ 450sce antibody, which were labelled with gold particles of varying diameter ( $5 \mathrm{~nm}, 10 \mathrm{~nm}$ each) could be observed on all the mitochondria of the bovine adrenal cortical cells. No heterogeneities as to the stainability for both ATP synthase and SCC were detected in mitochondria of the rat and bovine adrenal cortical cells.

These results indicate that in the rat and bovine adrenal cortical cells, both ATP synthase and SCC are evenly and simultaneously present on the inner membrane of all mitochondria. Hence, mitochondria in the adrenal cortical cell seem to be homogeneous in their steroid and ATP synthesizing abilities.
The steroid secretory cells possess several kinds of enzymes in their mitochondria which are essential to the steroid biosynthesis, such as side chain cleavage enzymes (SCC) and 11 $\beta$-hydroxylase.

We previously made a pre-embedding immunocytochemical study on the localization of cytochrome P-450 of SCC and cytochrome P-450 of $11 \beta$-hydroxylase (ISHIMURA et al., 1985), and found that these were present on the inner mitochondrial membranes of bovine adrenal cortical cells. This study also revealed the occurrence of two types of mitochondria, immunopositive and immuno-negative, for these enzymes. This led us to believe that the negatively stained mitochondria might be brought about by an inadequate penetration of the antibody, because both immunopositive and negative mitochondria showed no difference in the structure of cristae, a characteristic reflecting the functional state of mitochondria. However, Mitani et al. (1982), who observed a similar phenomenon, attributed the difference in immunostainability of the mitochondria to some functional heterogeneity.

It is well known that the most important and fundamental role of mitochondria is the supply of ATP which is synthesized by ATP synthase (ATP synthesizing enzyme). This leads to the interesting problem of whether or not the mitochondria of the adrenal cortex have the functional heterogeneity as to the production of ATP and synthesis of steroid hormones.

The present study aims to clarify the distribution of ATP synthase and SCC in mitochondria of rat and 
bovine adrenal cortical cells using both pre- and post-embedding immunocytochemical methods.

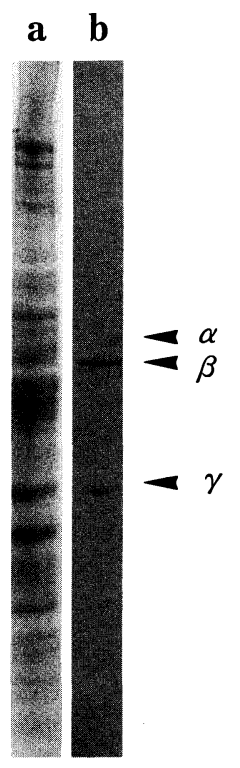

Fig. 1. a and b. Specificity of anti-ATP synthase antibody. a. Microsomal fraction of rat liver tissues is subjected to SDS-polyacrylamide gel electrophoresis. Proteins separated on gels are stained with Coomassie brilliant blue. b. Proteins separated under the same condition are transferred to nitrocellulose paper. Subsequently ATP synthase on the paper is labeled with $0.5 \%(\mathrm{v} / \mathrm{v})$ anti-ATP synthase antibody and peroxidase conjugated goat antirabbit IgG. ATP synthase is demonstrated by the peroxidase reaction with $\mathrm{DAB}$ and $\mathrm{H}_{2} \mathrm{O}_{2}$. The present immunoblotting examination shows that the antiserum we used specifically reacts with $\alpha, \beta$, and $\gamma$ subunits of ATP synthase.

\section{MATERIALS AND METHODS}

Young male Wistar rats were anesthesized and perfused via the left heart ventricle with $4 \%$ paraformaldehyde solution buffered at $\mathrm{pH} 7.4$ with Millonig's phosphate, and adrenal glands and liver were excised. The organs were cut into small pieces and immersed in the same fixative for $12 \mathrm{~h}$ at $4^{\circ} \mathrm{C}$.

Bovine adrenal glands were obtained at a local slaughterhouse. The glands were cut out within 20 min after death, cut into small pieces and immersed in the same fixative solution mentioned above.

For pre-embedding immunocytochemistry, after the fixation, the tissue samples were rinsed in phosphate buffered saline (PBS) solution containing 10\%, $15 \%$ and $20 \%$ sucrose $3-6 \mathrm{~h}$, respectively. Frozen sections cut in an Ames cryostat II (Miles) were mounted on albumin-coated glass slides and incubated in the first antibodies (rabbit antiserum against ATP synthase $(1: 500)$, anti-cytochrome P-450scc $(1: 100)$ (OXYgene, Dallas), anti-cytochrome P-450 ${ }_{11} \beta(1: 100)$ (a gift from Dr. M. OKAмото) overnight at $4^{\circ} \mathrm{C}$, treated with horse raddish peroxidase (HRP)-conjugated anti-rabbit IgG $(1: 100)$ for $4 \mathrm{~h}$ at room temperature, and then colored in a medium containing $0.005 \% 3-3^{\prime}$ diaminobenzidine and $0.03 \% \mathrm{H}_{2} \mathrm{O}_{2}$ for $5-10 \mathrm{~min}$ at room temperature. The sections were postfixed in $1 \%$ $\mathrm{OsO}_{4}$ solution buffered at $\mathrm{pH} 7.4$ with Millonig's phosphate for $30 \mathrm{~min}$, stained with $2 \%$ uranyl acetate solution, dehydrated in a series of graded concentrations of ethanol, and embedded in Epon epoxy resin. Ultrathin sections cut in a Reichert Ultracut $\mathrm{N}$ were observed without staining in a JEOL 1200EX electron microscope.

For post-embedding immunocytochemistry, tissues cut into small pieces were immersed in $4 \%$ paraformaldehyde solution for $2 \mathrm{~h}$ at $4^{\circ} \mathrm{C}$. After the fixation, the tissue samples were dehydrated in ethanol cooled to $-20^{\circ} \mathrm{C}$, and embedded in Lowicryl $\mathrm{K} 4 \mathrm{M}$

Fig. $2 \mathbf{a}$ and b. Pre-embeding electron microscopic immunocytochemistry of SCC (a) and $11 \beta$-hydroxylase (b) of bovine adrenal cortical cell. Immunoreaction products for the enzymes are localized on the inner membrane of some mitochondria $(M)$. Weakly or negatively stained mitochodria $(*)$ can be observed. a: $\times 40,200, \mathrm{~b}: \times 44,300$

Fig. $3 \mathbf{a}$ and b. Electron microscopic immunocytochemistry of ATP synthase of rat adrenal cortical cell. a. In the pre-embedding method, immunoreacted products are observed on the inner membrane of mitochondria $(M)$. A weakly reacted mitochondrion $(*)$ can be observed. b. In the post-embedding method, gold particles $(10 \mathrm{~nm}$ in diameter) are localized on all mitochondria $(M)$ of varying shape. $N$ nucleus, $L$ lipid droplet. a: $\times 23,800$, b: $\times 68,000$

Fig. 4 a and b. Post-embedding immunocytochemistry with double staining. Large gold particles (10 nm) indicate the localization of cytochrome P-450scc (arrows), and small gold particles $(5 \mathrm{~nm})$ show the localization of ATP synthase (arrow heads). Both sizes of gold particles are localized on the all mitochondria $(M)$. SER smooth endoplasmic reticulum. a: $\times 30,000, \mathrm{~b}: \times 90,000$ 

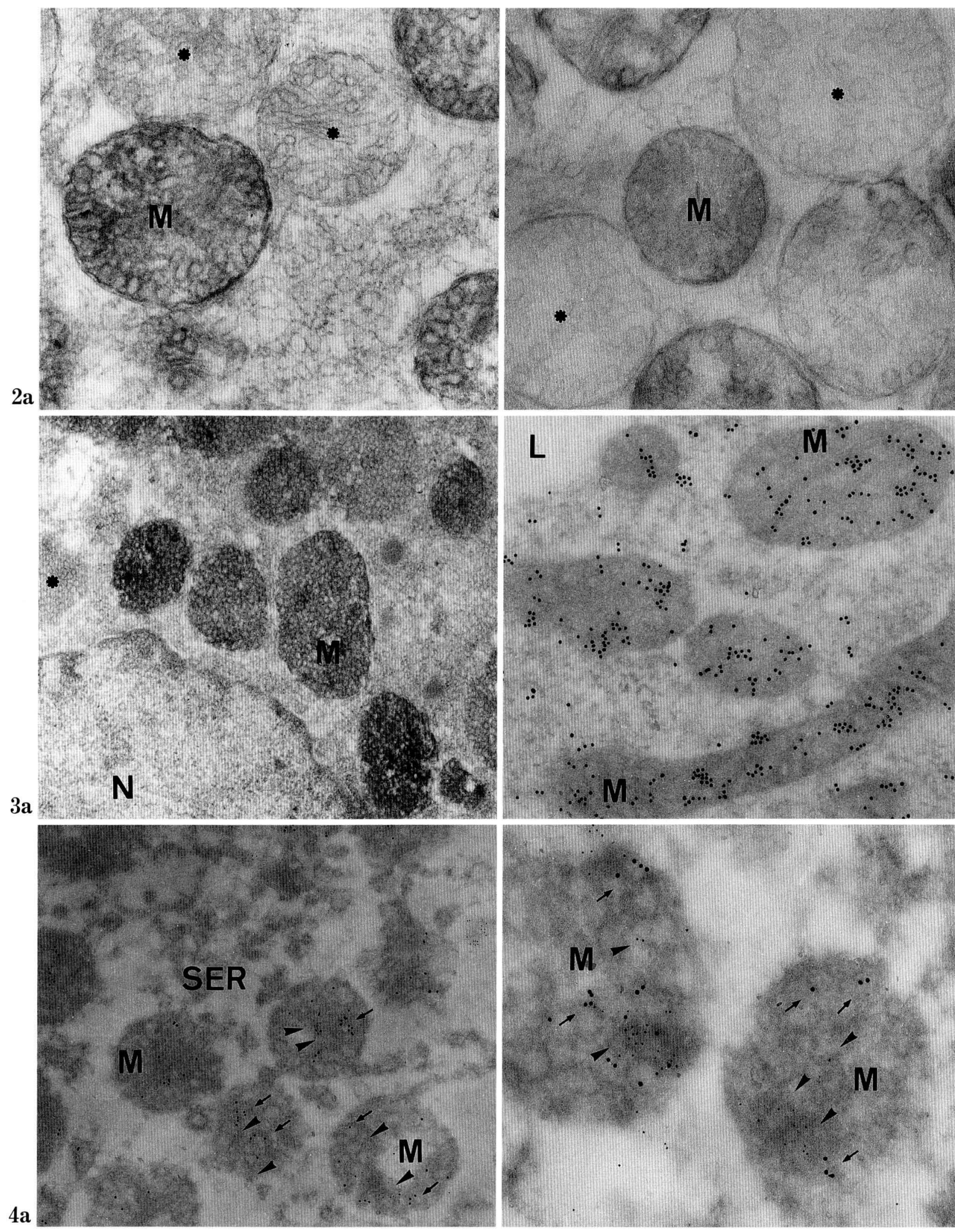

Figs. 2-4. Legends on the opposite page. 
at $-20^{\circ} \mathrm{C}$. Ultrathin sections mounted on nickel grids were incubated in the first antiserum, anti-cytochrome P-450scc $(1: 100)$ (OXYgene, Dallas) or anti-ATP synthase $(1: 500)$, for $4 \mathrm{~h}$ at room temperature, then treated with colloidal gold $(10 \mathrm{~nm}$ in diameter) conjugated anti-rabbit IgG for $2 \mathrm{~h}$ at room temperature. For double immunostaining, one side of each thin section mounted nickel grid was treated with P-450scc antiserum, then with the second antibody labeled with colloidal gold ( $10 \mathrm{~nm}$ in diameter). The other side of the grid was further treated with anti-ATP synthase antibody followed by incubation with the second antibody labeled with smaller colloidal gold (5 $\mathrm{nm}$ in diameter). They were then examined in a JOEL 1200 EX electron microscope.

The isolation and purification method of liver mitochondrial ATP synthase has been described elsewhere (HASHIMOTO et al., 1981). The specificity of anti-ATP synthase antibody was determined using the immunoblot method as follows. The mitochondrial fraction of rat liver was subjected to SDS-polyacrylamide gel electrophoresis according to the method of LAEMMLI (1970). Proteins separated on the gels were stained with Coomassie brilliant blue (Fig. 1a). Proteins separated under the same condition were blotted on a nitrocellulose paper as described by TowBIN et al. (1979). Then ATP synthase on the paper was labelled with $0.5 \%(\mathrm{v} / \mathrm{v})$ anti ATP synthase antibody and peroxidase-conjugated goat anti-rabbit IgG. Three subunits of ATP synthase $(\alpha, \beta$ and $\gamma)$ were demonstrated by the peroxidase reaction with $\mathrm{DAB}$ and $\mathrm{H}_{2} \mathrm{O}_{2}$ (Fig. 1b).

\section{RESULTS}

\section{Pre-embedding immunocytochemistry}

In bovine and rat adrenal cortical cells processed with the pre-embedding method, some mitochondria were positive for immunostaining of ATP synthase, SCC, and $11 \beta$-hydroxylase, while others were negative. In the immunopositive mitochondria, reaction products were evenly localized along the matrix side of the inner membranes of mitochondria (Figs. 2a, b, $3 a)$. Though each adrenal cortical cell had both positively and negatively stained mitochondria, no prominent ultrastructural differences were recognized between these mitochondria, which have not lamellar but tubulovesicular cristae. Other organelles such as smooth endoplasmic reticulum, Golgi apparatus and lipid droplets were entirely negative for the immunostaining. In control sections, the immunoreaction was completely negative.
The antibodies, anti-cytochrome P-450 scc and anti-cytochrome P-450 $0_{11} \beta$, cross-reacted with bovine adrenal gland cells, but did not have any cross-reactivity with rat adrenal gland cells.

\section{Post-embedding immunocytochemistry}

Gold particles showing the presence of ATP synthase were localized on all mitochondria of rat adrenal cortical cells, regardless of the shape of mitochondria (Fig. 3b). In the double immunostaining, both large (10 $\mathrm{nm})$ and small $(5 \mathrm{~nm})$ gold particles, showing the presence of side chain cleavage enzyme (SCC) and ATP synthase, respectively, were present on all the mitochondria of bovine adrenal cortical cells (Fig. 4a, b).

\section{DISCUSSION}

One of the important roles of mitochondria is the production of ATP. The synthesis of this compound, known to be catalized by ATP synthase is the ATP synthesizing enzyme. This enzyme is made up of two major parts: $F_{0}$ and $F_{1}$. It is well known that the $F_{1}$ part is composed of five subunits, $\alpha, \beta, \gamma, \delta$ and $\varepsilon$. In this study, we used an antiserum which specifically recognizes $\alpha, \beta$, and $\gamma$ subunits. Using this antiserum, we found that $\alpha, \beta$, and $\gamma$ subunits were evenly present along the inner mitochondrial membrane of some mitochondria by pre-embedding method, and also present on all the mitochondria of the adrenal cortical cells by the post-embedding method. In addition, both ATP synthase, which is a general enzyme to all the cells, and SCC, which is a special enzyme to steroid producing cells, are colocalized in all the mitochondria of the bovine adrenal cortical cells.

In our previous pre-embedding immunocytochemical study on the localization of cytochrome P-450scc and $\mathrm{P}-450_{11} \beta$, we found two types of mitochondria in a bovine adrenal cortical cell, positively stained mitochondria and negatively stained ones (ISHIMURA et al., 1985). Mitani et al. (1982) attributed this different stainability to the functional heterogeneity of mitochondria. However, we believed the results could be brought about by differences in antibody penetration, because no ultrastructural differences between positively and negatively stained mitochondria were detected. In the frozen section, some mitochondria maintained an intact form and intact mitochondrial membrane, but others did not. The antibodies (anticytochrome P-450scc antibody, anti-ATP synthase antibody, anti-cytochrome P-450 ${ }_{11} \beta$ antibody, and HRP-conjugated antibodies) have to pass two mitochondrial membranes (inner- and outer-mitochondrial 
membranes) to reach the antigens on the matrix side of the mitochondria. The antibodies barely penetrate the intact mitochondrial membrane, but easily come into the mitochondrial matrix through the broken portion of membranes. The penetration ability of antibodies has considerable influence on the immunostainability, and seems to follow an all-or-nothing law. In the post-embedding method, ultra-thin sections are so thin that the cutting parts of the intracellular organs including mitochondria are exposed to the surface of the section. Each antibody can easily react to each antigen on the surface of the innermitochondrial membrane, so that all the mitochondria are positively stained for the antibodies. Several years ago, GUEZE et al. (1987) demonstrated with the post-embedding method that cytochrome P-450scc and $\mathrm{P}-450_{11} \beta$ were equally localized in the same mitochondria. This means that no heterogeneity is present in mitochondria of the adrenal cortical cells as to the steroid synthesizing ability. Biochemical studies have reported that most of mitochondrial enzymes such as cytochrome P-450scc, P- $450_{11} \beta$, and many subunits of ATP synthase are synthesized on the ribosomes in the cytoplasm and then carried into mitochondria (SCHATZ and MASON, 1974; ANDERSON et al., 1981). Hence, it is more likely that all mitochondria of steroid producing cells are homogenous as to biosynthesis of steroid hormones and ATP. The present results clearly show that mitochondria of the adrenal cortical cell are homogenous in their ability for steroid synthesis and ATP production.

Acknowledgement. The authors thank Prof. Dr. H. FuJITA for valuable suggestions, and Prof. Dr. M. Окамото for providing the antibody (anti-cytochrome P-450 $0_{11} \beta$ ). We wish to thank Miss M. YамAMOTO and Miss J. NAKAMURA for typing the manuscript.

\section{REFERENCES}

Anderson, S., A. T. Bankier, B. G. Barrell, M. H. L. de Bruijn, A. R. Coulson, J. Drouin, I. C. Eperon, D. P. Nierlich, B. A. Roe, F. Sanger, P. H. Schreier, A. J. H. Smith, R. Staden and I. G. Young: Sequence and organization of the human mitochondrial genome. Nature 290: 457-465 (1981).
Gueze, H. J., J. W. Slot, K. Yanagibashi, J. A. Mc Cracken, A. L. Schwartz and P. F. Hall: Immunogold cytochemistry of cytochromes P-450 in porcine adrenal cortex. Two enzymes (side-chain cleavage and 11 beta-hydroxylase) are co-localized in the same mitochondria. Histochemistry 86: 551-557 (1987).

Hashimoto, T., Y. Negawa and K. Tagawa: Properties of binding site for adenine nucleotide on ATPase from yeast mitochondria. J. Biochem. 90: 1141-1150 (1981).

Ishimura, K., T. Yoshinaga, H. Fujita, S. Sugano, M. Окамото and T. YAmano: Light and electron microscopic immunohistochemistry on the localization of cytochrome P-450 of the side chain cleavage system and of cytochrome P-450 of $11 \beta$-hydroxylase in the bovine adrenal cortical cells. Arch. Histol. Jap. 48: 541-456 (1985).

LAEмmLI, U. K.: Cleavage of structural proteins during the assembly of the head of bacteriophage $\mathrm{T}_{4}$. Nature 227: 680-685 (1970).

Mitani, F., T. Shimizu, R. Ueno, Y. Ishimura, S. IzUmi, N. Komatsu and K. Watanabe: Cytochrome P-450 ${ }_{11} \beta$ and P-450scc in adrenal cortex: Zonal distribution and intramitochondrial localization by the horseradish peroxidase-labeled antibody method. J. Histochem. Cytochem. 30: 1066-1074 (1982).

Schatz, G. and T. L. Mason: The biosynthesis of mitochondrial proteins. Ann. Rev. Biochem. 43: 51-87 (1974).

Towbin, H., T. STaEhelin and J. Gordon: Electrophoretic transfer of proteins from polyacrylamide gels to nitrocellulose sheets: procedure and some applications. Proc. Nat. Acad. Sci. USA 76: 4350-4354 (1979).
平林 朋子

565 吹田市山田丘 2-2

大阪大学医学部

第三解剖学教室

Dr. Tomoko Hirabayashi

Department of Anatomy

Osaka University Medical School

2-2 Yamadaoka, Suita

565 Japan 